\title{
Perspetivas e entendimentos dos praticantes portugueses de karaté sobre o conceito de Budô
}

\author{
Vitor ROSA* \\ Université Paris Ouest Nanterre La Défense (Francia)
}

Recepción: 02/10/2015; Aceptación: 12/01/2016; Publicación: 14/01/2016.

ORIGINAL PAPER

\section{Resumo}

Inserido no âmbito da sociologia do desporto, este artigo tem por objetivo estudar a perspetiva e entendimentos dos praticantes de artes marciais e desportos de combate, em particular o karaté, em Portugal, sobre o conceito de "Budô". Para este estudo, recorreu-se à metodologia extensiva e a aplicação de diversas técnicas de investigação social (entrevista semi-diretiva, inquérito por questionário). A mostra foi de 244 praticantes de karaté avançados (cintos castanho e negro), a nível nacional. Os resultados revelam que os praticantes de karaté concebem a sua prática como expressão do Budô, reproduzida de forma dominante pelos agentes de ensino (treinadores), através de imagens, símbolos, veiculação de valores. Os karatecas dão especial importância aos códigos e normas de conduta associados aos princípios éticos do Budô e à manutenção dos ritos e símbolos oriundos do país do Sol-Nascente. Os praticantes que mais valorizaram o Budô são afetos ao mesmo estilo de prática, por isso, o estudo não pode ser generalizável a todos os praticantes de karaté.

Palavras-chave: Artes marciais; Artes marciais japonesas; Desportos de combate; Budô; Bushidô.

\section{Perspectives and understandings of Portuguese karate practitioners on the concept of Budo \\ Abstract}

This article, which falls within the scope of the sociology of sport, aims to study the perspective and understanding of martial and combat sports practitioners, especially of karate, in Portugal, on the concept of "Budo". For this study, we used an extensive methodology and applied various techniques of social research (semi-directive interview, questionnaire survey). The sample was composed of 244 advanced karateka (brown and black belt) at the national level. The results showed that karate practitioners conceive their practice as an expression of Budo, reproduced in a dominant way by teaching staff (trainers), through images, symbols and values. Karatekas gave special importance to the codes and standards of conduct associated with the ethical principles of Budô and the maintenance of the rites and symbols from the country of the Rising Sun. Karatekas who most valued Budo practiced the same karate style, therefore, the study may not be generalized to all practitioners of karate.

Keywords: Martial Arts; Japanese Martial arts; Combat Sports; Budo; Bushido.

\section{Perspectivas y concepciones de practicantes portugueses de karate sobre el budo}

\section{Resumen}

Este artículo, que se ubica en el ámbito de la sociologia del deporte, tiene por objetivo estudiar la concepción que tienen los practicantes de artes marciales y deportes de combate, específicamente de karate, sobre el "budo". Se utilizó una metodología extensiva y aplicaron diversas técnicas de investigación social (entrevistas semi-dirigidas y encuestas mediante cuestionarios). La muestra fueron 244 karatekas de nivel avanzado (cinturones negros y marrones), a nivel nacional. Los resultados mostraron que los karatekas conciben su práctica como una expresión del budo, que se reproduce de forma dominante por los enseñantes (entrenadores), a través de imágenes, símbolos y valores. Los karatekas dan especial importancia a los códigos y normas de conducta asociados a los principios éticos del budo, así como al mantenimiento de los ritos y símbolos oriundos del país del Sol Naciente. Los karatekas que más valoran el budo practican el mismo estilo, y por ello este estudio no es generalizable a todos los practicantes de karate.

Palabras clave: Artes marciales; Artes marciales japonesas; Deportes de combate, Budo; Bushido.

\section{Introdução}

As artes marciais são produtos culturais complexos, cuja prática se pode relacionar com motivações com a defesa, competição, lazer, canalização da agressividade, educação física e social, saúde, ou procura de uma filosofia (Ehrenberg, Yahri, \& Zylberman, 1975; Priest \& Young, 2015; Svinth, 2010). Outros investigadores, como Loudcher e Renaud (2011a,b), veem na prática das artes marciais fatores educacional, pedagógico e de integração, sobretudo dos indivíduos em

*E-mail: vitor.vr@u-paris10.fr. 
dificuldades de inserção. Recorrendo a uma expressão de Boltanski (1971), as artes marciais prestam-se a diferentes "usos sociais" que variam segundo os contextos, os atores em presença e os motivos/compromissos do momento.

As artes marciais conheceram na Ásia uma modernização e uma aculturação importantes desde finais do século XIX e durante o século XX, designadamente sob a influência da cultura ocidental. Estruturadas inicialmente em torno de escolas e de mestres, perpetuadas principalmente em segredo, as artes marciais foram absorvidas por diversas instituições públicas, nomeadamente as federações desportivas e os estabelecimentos de ensino, designadamente as universidades (Braunstein, 2001). 0 desenvolvimento das artes marciais na Europa, e em particular em Portugal, observa um movimento associativo, com períodos e ritmos variáveis. 0 jiu-jitsu, introduzido na Europa no final do século XIX e início do século XX, e que não é menos do que uma prática de circo e de music-hall (Brousse, 2000; Brousse \& Matsumoto, 1999; Gutiérrez-García, 2004; GutiérrezGarcía, Rosa, \& Pérez-Gutiérrez, 2010), serve de base para a introdução do judô durante as décadas seguintes. 0 karaté e o aikido desenvolveram-se nos anos 1960 (Braunstein, 2001), e o taekwondo, o kendo e o iaido propagam-se, na Europa, durante a segunda metade desta década (Rosa, 2007, 2008, 2015).

O número de praticantes sublinha a evolução e reconhecimento das artes marciais. Estes desenvolvimentos acompanham os movimentos identitários, articulando-se em duas dimensões, permitindo a cada prática definir a sua singularidade, a sua autenticidade e a sua supremacia: a eficácia combativa e a relação com as tradições (Theeboom \& Knop, 1999; Verthonghen, Theeboom, \& Cloes, 2012). Para o caso do karaté, para além da eficácia combativa e a relação com as tradições, desenvolve-se, também em Portugal, a dimensão competitiva, resultando, inclusivamente, na existência de duas federações de karaté com objetivos diferentes (Rosa, 2007). Outros setores (profissionais e sociais) também sublinham o interesse das artes marciais. Elas são particularmente presas numa perspetiva utilitária nos serviços ou instâncias encarregadas da segurança civil e militar, combinando finalidades higiénicas e defesa pessoal. Em suma, estes fundamentos culturais são a fonte de identidade, de diversidade e do sucesso diferenciado das artes marciais. Cada disciplina propõe várias modalidades mais ou menos eufemizadas e ritualizadas, tendo em vista diversas finalidades, uma relação com o corpo e a estética, de normas e valores (Champault, 2001; Clément, 1985, 2001; Gaudin, 2009).

Sem dúvida, as "técnicas de corpo" (Mauss, 1950), ocupam um lugar central nas artes marciais (Min-Ho, 1999). Segundo Mauss (1950, p. 365), a "técnica" é um "ato tradicional e eficaz" e as "técnicas do corpo" são "as formas como os homens, sociedade em sociedade, de uma forma tradicional, sabem se servir do seu corpo". Ao serviço de uma eficácia máxima no combate, as técnicas corporais das artes marciais asiáticas constituem uma arte, permitindo parar a violência, estando marcadas por valores morais e de aspetos filosóficos e espirituais, inspirados nomeadamente do taoísmo, do budismo, do confucionismo e do xintoísmo. Entre estes se incluem o conceito ligado às artes marciais japonesas de Budô.

São poucos os estudos científicos que evocam o conceito de Budô, dando a palavra aos praticantes (Rosa, 2007, 2008; Rosa \& Stoleroff, 2008). Assim, neste artigo, procurámos contribuir com elementos de reflexão e com resultados concretos. Para isso, vamos começar por esclarecer os conceitos de Budô e Bushidô, continuando com a descrição de uma investigação destinada a descobrir a percepção que deste conceito têm os praticantes de karatê portugueses.

\section{Os conceitos e os significados de Budô (e Bushidô)}

Segundo Tokitsu $(2000,2001)$ o conceito de "Budô" implica uma complexidade de considerações que, a nosso ver, potencialmente diferenciam a prática das artes marciais "orientais" de quaisquer outros desportos. 0 termo "Budô", palavra de criação japonesa, compõe-se de um conjunto de duas palavras chinesas: $w u$ (japonês: $b u$ ), guerreiro, armas, e dao (japonês: dô), via, caminho em direção ao conhecimento, com a conotação moral do aperfeiçoamento de si mesmo. Dito de outro modo, do japonês corrente, o caractere $b u$ significa o que é viril e forte, e reenvia para as categorias de potência bui e bravura buyû.

Rev. Artes Marciales Asiát., 10(2), 124-134 2015 
Segundo Funakoshi (2001, p. 125), existe no Japão uma veneração por tudo o que toca ao mundo guerreiro, veneração que explica a "predileção pelos pronomes masculinos". Na época de Edo (1603-1868), durante o qual o Japão se fecha ao Ocidente, a palavra "Budô" assume um sentido mais amplo. Ela designa sempre uma via que deve seguir o guerreiro, englobando todos os Bugei (arte militar tradicional japonesa), diferenciadas em diferentes disciplinas sistematizadas em imensas escolas, mas ele assume, sobretudo, uma conotação ética mais clara ao ponto de se confundir com o termo Bushidô, a via do samurai. Nesta época para se designar as diferentes disciplinas empregava-se geralmente as palavras do sufixo jutsu (técnica): jujutsu, kenjutsu, kyujutsu, etc. $O$ hábito atual é de utilizar os termos com o sufixo dô (judô, kendô, kyudô, etc.), quando a sociedade japonesa, em plena agitação social, se abria à cultura ocidental. Estes termos conheceram uma vaga crescente, quando se deu o aumento do militarismo, depois durante a guerra, onde os ensinamentos do Budô tornaram-se obrigatórios nas escolas para fortificar as virtudes guerreiras e, eventualmente, servir no combate. 0 desenvolvimento das artes marciais na época Edo não é paradoxal. Ela explica-se pelo fato das artes marciais serem consideradas, pela sua vertente formativa, como um elemento maior na educação do samurai e como parte integrante do Bushidô, nova palavra que designa o código moral do guerreiro, suplantando outras antigas expressões, como "mononofu no michi" (Briot, 2001, p. 26).

De notar que com o período Edo a paz se instala, um mercado nacional se constitui, uma economia monetária se desenvolve. Os Bushi (classe social) conhecem raramente os combates reais e alguns passam por dificuldades, nomeadamente em encontrar os meios de subsistência. Daqui em diante, é a "sala", sob o olhar do mestre remunerado, onde os japoneses podem lutar e rivalizar. Assiste-se também à eclosão de escolas de artes marciais. Aqueles que ensinam nesses locais têm tendência a codificar o seu saber-fazer, a apresentar as técnicas-receitas melhores do que os seus concorrentes, universalmente reprodutíveis e suscetíveis de serem ensinadas a todas as pessoas.

Quando o Ocidente começa a impor a sua supremacia militar ao Japão, em 1850, por razões económicas, este, em grande parte descentralizado, não conseguiu resistir. Com a audácia do comandante Perry, em 1854, o Japão é obrigado a abrir os seus dois portos aos navios americanos e de assinar os acordos comerciais. 0 país acolhe mal estas concessões que mergulha o Japão num período de guerras civis e de grande desordem. Com a queda do governo do Tokugawa e a restauração do imperador Meiji, em 1868, o novo poder político e administrativo apoia-se nos jovens samurais, encarregados de reestabelecer o Estado e de modernizar o sistema militar (Braunstein, 2001).

Na Era Meiji (1868-1912), e segundo Briot (2001), os dois termos (Budô e Bushidô) se diferenciam e seguem destinos opostos. 0 Bushidô passa a ser o suporte espiritual de japoneses militantes patriotas. A palavra é popularizada no ocidente pela obra idealista Bushidô: the soul of Japan, do protestante cosmopolita Nitobe Inazô (1905). Segundo Loudcher e Renaud (2011a), na Era Meiji as artes marciais participam plenamente ao movimento de uma reforma social e nacional. A elite que estava no poder, apoiando-se em micronacionalismos regionais, conduz as iniciativas bélicas do país (guerra com a China em 1895 e depois com a Rússia em 1905) e à renovação das artes marciais japonesas orquestradas pela Dai Nippon Butokukai (Sociedade das Virtudes Marciais do Grande Japão), criada em 1895. 0 seu Imperador Mutsuhito (1852-1912) simboliza o fim da época feudal e dos shoguns (generais). O Japão entra no mundo moderno do capitalismo (Gravereau, 1990).

No pós-guerra, seguindo uma via bem diferente, a palavra Budô conheceu uma nova forma e desenvolvimento mundial através das artes marciais (judô, karaté, aikido, kendo, etc.), assimiladas a disciplinas desportivas. De referir que o karaté é também karaté-do. 0 "do", aliás, foi exigência da Dai Nippon Butokukai, tal como a mudança de nome de Tode para Karate-Do (note-se que o Tode era o nome original em Okinawa). Note-se que depois da guerra, e de um curto tempo de interdição das disciplinas japonesas de combate pela armada americana de ocupação, as diferentes federações desportivas procuraram vulgarizar estes novos termos. Com a derrota do Japão em 1945, o Bushidô, como "eficácia de combate", na sua forma mais extremista e mórbida, renasce das cinzas através da ação política e literária de Mishima Yokio (1925-1970), tergivando os "valores característicos da raça" (Chamberlain, 1931, p. 75). 
A palavra Budô dá lugar à criação de neologismos: kobudô e shinbudô (ou gendai Budô): "Budô antigos" e "Budô novos" (ou Budô contemporâneos) (Draeger, 1973a,b). 0 primeiro designa a arte das escolas de armas. 0 segundo encerra as artes marciais de origem japonesa. Atualmente, estas designações ampliaram os seus significados entendo-se como a escola de armas (primeiro) e as artes marciais de origem de japonesa (o segundo). A palavra Budô conota uma certa ideia de "japonitude", ou seja, o termo abrange as práticas de pertença à "tradição japonesa".

Segundo Funakoshi (2001), os manuais de instrução antes da guerra, que tratam do Budô, do Bushidô ou de Mononofu no michi, revelam que a aceção primitiva de bu é um desejo de paz. No primeiro ensaio japonês sobre as artes marciais concluído depois da guerra, Budô hôkan (1983), os autores são unânimes em referir este sentimento.

Sanzô (1967) refere que a nomeação, em 1942, do Primeiro-ministro no lugar de diretor da "Grande Associação Nipónica de Moral Guerreira", Dai Nippon Butokaikai, foi uma ingerência política significativa no domínio das artes marciais. Foi um retrocesso, na sua perspetiva. Um retrocesso porque a abolição da nobreza, com a publicação dos decretos obrigam os samurais a cortar o cabelo e a entregar as armas, colocando fim a uma classe social (os bushi) e fazer nascer uma nação moderna. Ora, na ala direita da política de reforço económico e militar, foram introduzidos nos programas escolares as artes marciais e o treino militar. 0 espírito kamikaze (próprio do Japão), e que surpreendeu os aliados e adversários, "funda-se na mentalidade das artes marciais" (Funakoshi, 2001, p. 128).

Funakoshi $(1979,2001)$ expõe uma ideia interessante sobre as artes marciais. Com base na aplicação de um inquérito por questionário aos japoneses, em 1979, a partir de 2.939 termos, vocabulário relativo às artes marciais, concluiu que se pode considerar dois pontos de vista japonês sobre as artes marciais. 0 primeiro, elogioso, que exprime o patriotismo, que elas são uma filosofia positiva de ação, fundamento da mentalidade japonesa. É a partir desta filosofia que se elabora as reflexões sobre o mundo da Via e os princípios imutáveis que regem a ação humana. Pode-se citar os sete princípios da via do guerreiro: a sabedoria, a bondade, a coragem, a simpatia, a lealdade, a verdade e a honra. Segundo este ponto de vista, com a prática das artes marciais procura-se a felicidade-alegria, a razão de viver, a realização humana e a eficácia social, assim como a honra de se ser japonês e o gosto pela tradição, das emoções e dos valores. 0 segundo ponto de vista, exprime a existência de uma consciência negativa das artes marciais, uma aversão impulsiva. Os qualificativos fora de moda, reacionárias, feudais, exprimem a crença de que elas são facilmente manipuláveis com fins políticos e de que se ligam ao militarismo. Assusta ver a violência direta, considerada como uma selvajaria, um retrocesso civilizacional (Elias, 2006). A conceção das artes marciais evoluiu ao longo da história, aproximando-se ou afastando-se do sentido original do kanji $b u$ e varia segundo a experiência de cada um e as diferentes sensibilidades devidas à idade e género.

Contrariamente a uma ideia vigente no meio das artes marciais, para o sociólogo japonês Tokitsu $(2000,2001)$ o Budô não saiu da prática guerreira das artes marciais. É uma conceção moderna que visa a formação global do homem, intelectual e físico, através de disciplinas tradicionais de combate. 0 Budô evoca uma imagem séria, de severidade, de ritual, de respeito pelos mais antigos e pelos mestres, de meditação silenciosa, etc. (Tokitsu, 2000). Na argumentação do autor, o Budô japonês é limitado a um quadro reduzido. Uma das principais razões é por não ter encontrado o seu espaço na Europa, onde ele é situado à margem do desporto. Tokitsu (2001) refere que no Japão existe uma tendência para se definir o Budô pelo seu aspeto de austeridade e de dureza. Dando o exemplo do karaté, o autor sublinha que se trata de uma prática dura, na qual não se evita os combates K.O. e afasta a ideia de competição. Para si, a noção de Budô, implica refletir sobre a prática técnica das artes marciais, $b u$, em relação com a noção da via, dô. 0 kendo é por si considerado como a única disciplina do Budô que preserva a ideia original no seu pleno sentido através da prática de combate. Em outras disciplinas ora se confundem com os desportos de combate, ora se limitam à prática de katas, o que dá a impressão de "práticas folclóricas" (Tokitsu, 2001, p. 153). Assim sendo, é da responsabilidade dos mestres e adeptos japoneses preservar e desenvolver um património cultural, o Budô, e comunicar e transmitir aos outros (Nakiri, 2015). Para isso, é necessário ter uma visão abrangente do mundo do Budô, por forma a analisar e compreender a situação atual do Japão e de outros países, e de elaborar uma teoria e um método de 
comunicação do Budô. Segundo Cynarski e Obodynski (2009, p. 2), "Atualmente, o Budô é percebido como uma forma moral não agressiva, um meio educacional, uma arte de vida ou um antigo normativo sistema de Bushidô - o código de honra da cavalaria japonesa."

\section{Metodologia}

O conceito de Budô nas artes marciais, nomeadamente no karaté, é, muitas vezes, vago para os praticantes de artes marciais, sobretudo para os iniciantes, como se viu no ponto precedente. É, assim, importante perceber como os praticantes avançados os apreendem e manifestam. A nossa pergunta de partida é a seguinte: como é que o conceito de Budô é percebido pelos praticantes e como se manifesta? Para a discussão dos resultados, serão mobilizadas algumas teorias sociológias, entre as quais a de Bourdieu (1979), com o seu determinismo, e a de Crozier e Friedberg (1977), com a estratégia dos atores.

0 nosso estudo foi abrangente. Para este artigo, apenas se mobilizaram alguns métodos e técnicas de investigação. Assim, recorremos ao método de análise extensiva (ou de medida). Tratase de uma abordagem metodológica de investigação adequada quando se procura compreender, explorar ou descrever acontecimentos e contextos complexos, nos quais estão simultaneamente envolvidos diversos fatores (Quivy \& Campenhoudt, 1998).

No caso das técnicas de pesquisa, recorremos à entrevista semi-diretiva e ao inquérito por questionário. Nas entrevistas semi-diretivas, procurámos entrevistar alguns praticantes de karaté e dirigentes. No inquérito por questionário, o universo de análise foi de 244 praticantes avançados de karaté (cinto castanho e negro), em Portugal. 0 inquérito utilizado foi extenso (58 questões sobre conhecimentos, opiniões, intenções e comportamentos relacionados com o karaté e com a vida em geral). A primeira versão do questionário foi ajustada após os resultados do pré-teste. Para este artigo científico, mobilizou-se apenas algumas questões, como, por exemplo, "a orientação ou conceção do karaté que os praticantes privilegiam (vertente pessoal)" (budô, prática desportiva lúdica, competição amadora, alta competição); "a orientação da prática do karaté que é privilegiado no centro de prática (vertente externa, direcionada pelo treinador)", segundo o estilo de karaté praticado. Existe, assim, duas formas de estar: aquilo que é feito e promovido (pelo treinador) e aquilo que o praticante desejava que fosse. Embora simples, estas questões permitirão dar resposta aos nossos objetivos de estudo. 0 inquérito, desenvolvido por Rosa e Stoleroff (2008), foi aplicado durante 2007 e 2008, seguindo a amostragem "bola de neve" e os extensos resultados têm vindo a ser explorados paulatinamente.

\section{Resultados e discussão}

\subsection{Resultados das entrevistas}

Que significado dão os praticantes de artes marciais e desportos de combate, em particular do karaté, a este conceito de Budô? Para responder a esta questão recorremos a alguns excertos de entrevistas semi-diretivas efetuadas. Vejamos alguns testemunhos de praticantes (instrutores e dirigentes):

Se observarmos conceptualmente, podemos traduzir este termo como a "via do guerreiro". Se fosse bujutsu, estaríamos a falar do guerreiro no seu sentido mais procedimental, de combate real, de guerra. Mas não. Falamos da via, no seu sentido simbólico, onde o marcial enquanto representação guerreira, representa um caminho de construção humana. O Budô é sustentado por práticas de combate não sendo, contudo, estas o seu principal objetivo. Estas são o instrumento de desenvolvimento da identidade do guerreiro. $\mathrm{E}$ a identidade do guerreiro regese por princípios de respeito, honra, empreendedorismo, resiliência. A metáfora do combate desportivo (competitivo ou não), ou simbólico, dá resposta à necessidade de construção destes aspetos do carácter humano. E estes treinam-se no dojo enquanto microcosmos de educação social. (Bruno Rosa, Shotokai, $1 .^{\circ}$ dan)

Para mim, o Budô é a forma interior e pessoal de interpretar a prática marcial e modelo de vivência dentro da modalidade. Num arquétipo mais tradicionalista, os princípios associados à 
ética marcial oriental através dos tempos e implícita no karaté moderno, menos visíveis ou mediáticos, traduzem-se por via de gestos de etiqueta, de filosofia do combate, de respeito entre vencedores e vencidos, por quem nos ensina, no equilíbrio de valores e comportamentos. Julgo que hoje o Budô não se leciona a partir de qualquer paradigma, mas sim a partir da experiência com que cada mestre, instrutor e discípulos, percorrem e consolidam uma escola, um estilo, uma associação. (Nuno Dias, Shukokai, 2.o dan)

O conceito de Budô tem vindo a acompanhar a evolução das sociedades. Se na origem tinha a ver com artes marciais, na era da "guerra das estrelas" o carácter marcial ficou reservado só para o "inimigo interno". Este sempre existiu e seria sempre necessário obter vitórias sobre ele, para se conseguir com segurança defrontar fisicamente e na guerra os inimigos externos. Hoje, no Budô a possibilidade que existe de confronto "de mãos vazias", com um inimigo externo é diminuta, mas talvez os aspetos que se prendem com a formação do carácter, respetivos valores e princípios estejam menos presentes nas sociedades atuais. Assim, julgo que o conceito Budô permanece atual, sendo esse Do no karaté-do praticado em todos os momentos e técnicas. Como exemplos clássicos e básicos, pode-se referir o ato de suportar uma posição mais incómoda, trabalhar no limite da exaustão física, "aplanar" as nossas emoções durante o treino. Como exemplos mais avançados pode-se referir a aplicação permanente (dentro e fora do treino) dos 20 Princípios Fundamentais, enunciados pelo Mestre Gichin Funakoshi. Entendo o Budô, no contexto atual, como uma forma de estar perante a prática de uma determinada modalidade, no caso o karaté, em que a prática e o ensino da mesma devem demonstrar o respeito pelo próximo e pela integridade humana, naquilo que considero uma arte de combate. (José Patrão, Shotokai, $5 .^{\circ}$ dan)

"Para mim, o Budô é a forma interior e pessoal de interpretar a prática marcial e modelo de vivência dentro da modalidade". "Entendo o Budô, no contexto atual, como uma forma de estar perante a prática de uma determinada modalidade, no caso o karaté". Estas duas passagens das entrevistas efetuadas e transcritas anteriormente, permitem-nos afirmar de que os praticantes interpretam os conceitos e apropriam-se deles à sua maneira e consoante o seu estilo de vida. A distinção entre Budô e o desporto lúdico ou competitivo é uma questão de se "estar" na prática.

Se cruzarmos os dados empíricos destas entrevistas e a teoria sociólogica, podemos dizer que o ator individual, numa organização, "dispõe de uma margem de liberdade irredutível no prosseguimento das suas atividades" (Crozier \& Friedberg, 1977, p. 46). Existe também uma forma de falar, de vestir, de comer ou de se apreciar certas práticas, segundo o meio social. Dito de outro modo, a posição ocupada por cada indivíduo leva a uma visão e um comportamento particulares em termos de gostos, de atitudes e de julgamentos (Bourdieu, 1979).

\subsection{Resultados dos inquéritos por questionário}

Dos 244 praticantes inquiridos, $74,2 \%(n=181)$ não pratica competição, contra $23,0 \%(n=$ 56) que diz que pratica karaté na sua vertente de competição institucionalizada ( 7 inquiridos não responderam a esta questão). Os Gráficos 1 e 2 realçam um aspeto muito interessante de como os praticantes de karaté entendem a sua prática. No entanto, é preciso referir que a validade das nossas respostas depende do pressuposto de que os respondentes entendem bem o significado dos termos das diversas opções. Presumimos que se possa atribuir validade às respostas dadas precisamente porque os inquiridos são detentores de graduações técnicas superiores, e que, em princípio, foram sendo iniciados nos sentidos da terminologia fundamental do karaté.

Os Gráficos 1 e 2 mostram que a maior percentagem dos nossos respondentes, mas não a maioria, indica a preferência por uma conceção da sua prática enquanto Budô. Esta questão é ainda comprovada com a importância que os praticantes dão aos códigos das normas de conduta do dojo associado aos princípios éticos do Budô e à manutenção dos ritos e símbolos oriundos do país do Sol-Nascente (Baudry, 1998). Se cruzarmos os dados, temos a seguinte distribuição entre a orientação ou conceção do karaté que mais privilegia e o estilo de karaté praticado (cf. Tabela 1) e segundo a orientação que é mais privilegiada no dojo e o estilo de karaté praticado (cf. Tabela 2). No primeiro quadro houve 14 indivíduos que não sabem ou não quiseram responder a esta questão. No segundo quadro, 21 indivíduos não responderam a esta questão. 


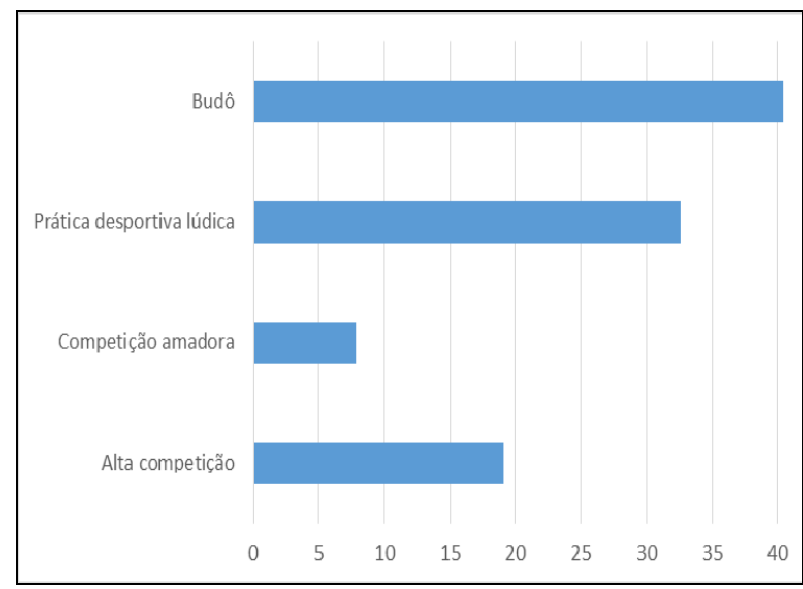

Gráfico 1. Distribuição dos inquiridos, segundo a conceção ou orientação do karaté que privilegiam, em percentagem

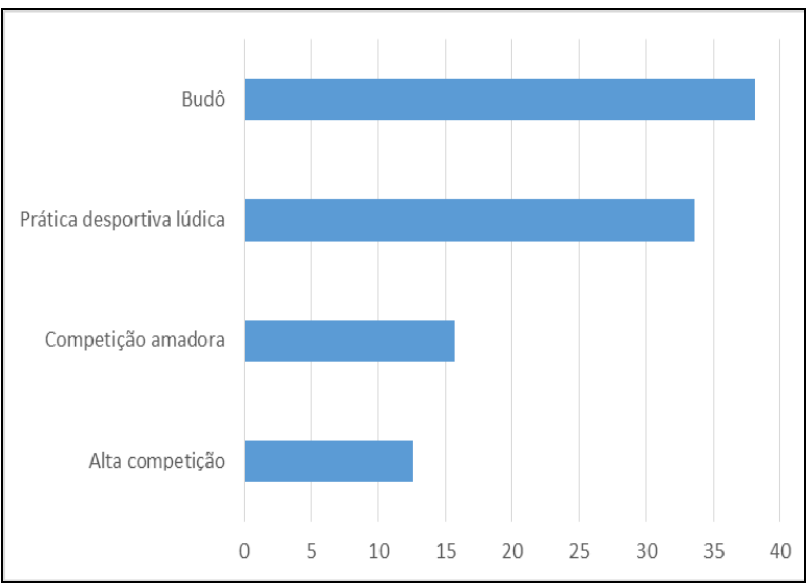

Gráfico 2. Distribuição dos inquiridos, segundo a conceção ou orientação do karaté que é privilegiada nos centros de prática, em percentagem

Tabela 1. Cruzamento segundo a orientação do karaté que mais privilegia e o estilo de karaté praticado.

\begin{tabular}{lccccccc}
\hline \multirow{2}{*}{ Orientação } & & \multicolumn{7}{c}{ Qual é o estilo de karaté que pratica? } & \multirow{2}{*}{ Total } \\
& & Shotokai & Shotokan & Goju-Ryu & Wado-Ryu & Shito-Ryu & \\
\hline Alta competição & $n$ & 14 & 15 & 5 & 9 & 1 & $\mathbf{4 4}$ \\
& $\%$ & $6,1 \%$ & $6,5 \%$ & $2,2 \%$ & $3,9 \%$ & $0,4 \%$ & $19,1 \%$ \\
\hline Competição amadora & $n$ & 6 & 6 & 5 & 1 & 0 & $\mathbf{1 8}$ \\
& $\%$ & $2,6 \%$ & $2,6 \%$ & $2,2 \%$ & $0,4 \%$ & $0,0 \%$ & $7,8 \%$ \\
\hline Prática desportiva lúdica & $n$ & 37 & 15 & 12 & 5 & 6 & $\mathbf{7 5}$ \\
& $\%$ & $16,1 \%$ & $6,5 \%$ & $5,2 \%$ & $2,2 \%$ & $2,6 \%$ & $32,6 \%$ \\
\hline Budồ & $n$ & 45 & 20 & 16 & 7 & 5 & $\mathbf{9 3}$ \\
& $\%$ & $19,6 \%$ & $8,7 \%$ & $7,0 \%$ & $3,0 \%$ & $2,2 \%$ & $40,4 \%$ \\
\hline Total & $n$ & $\mathbf{1 0 2}$ & $\mathbf{5 6}$ & $\mathbf{3 8}$ & $\mathbf{2 2}$ & $\mathbf{1 2}$ & $\mathbf{2 3 0}$ \\
& $\%$ & $44,3 \%$ & $24,3 \%$ & $16,5 \%$ & $9,6 \%$ & $5,2 \%$ & $100,0 \%$ \\
\hline
\end{tabular}

Tabela 2. Cruzamento segundo a orientação que é mais privilegiado no dojo e o estilo de karaté praticado.

\begin{tabular}{|c|c|c|c|c|c|c|c|}
\hline \multirow{2}{*}{ Orientação } & & \multicolumn{5}{|c|}{ Estilo de karaté praticado no seu dojo } & \multirow{2}{*}{ Total } \\
\hline & & Shotokai & Shotokan & Goju-Ryu & Wado-Ryu & Shito-Ryu & \\
\hline \multirow[t]{2}{*}{ Alta competição } & $n$ & 10 & 8 & 4 & 5 & 1 & 28 \\
\hline & $\%$ & $4,5 \%$ & $3,6 \%$ & $1,8 \%$ & $2,2 \%$ & $0,4 \%$ & $12,6 \%$ \\
\hline \multirow[t]{2}{*}{ Competição amadora } & $n$ & 9 & 15 & 6 & 3 & 2 & 35 \\
\hline & $\%$ & $4,0 \%$ & $6,7 \%$ & $2,7 \%$ & $1,3 \%$ & $0,9 \%$ & $15,7 \%$ \\
\hline \multirow[t]{2}{*}{ Prática desportiva lúdica } & $n$ & 38 & 16 & 12 & 6 & 3 & 75 \\
\hline & $\%$ & $17,0 \%$ & $7,2 \%$ & $5,4 \%$ & $2,7 \%$ & $1,3 \%$ & $33,6 \%$ \\
\hline \multirow[t]{2}{*}{ Budô } & $n$ & 45 & 13 & 16 & 5 & 6 & 85 \\
\hline & $\%$ & $20,2 \%$ & $5,8 \%$ & $7,2 \%$ & $2,2 \%$ & $2,7 \%$ & $38,1 \%$ \\
\hline \multirow[t]{2}{*}{ Total } & $n$ & 102 & 52 & 38 & 19 & 12 & 223 \\
\hline & $\%$ & $45,7 \%$ & $23,3 \%$ & $17,0 \%$ & $8,5 \%$ & $5,4 \%$ & $100,0 \%$ \\
\hline
\end{tabular}

A dimensão de praticantes de karaté Shotokai parece influenciar a quantidade de praticantes que assumem o Budô como orientação preferencial, uma vez que constituem cerca de $46 \%$ do total.

Como se pode verificar pelo Gráfico 3, a maioria dos praticantes atribui grande importância ao código das normas de conduta do dojo associado aos princípios éticos do Budô à manutenção dos ritos e símbolos oriundos do Japão na prática do karaté. Com menor importância os praticantes 
consideram a dimensão espiritual da modalidade e a introdução do karaté no programa dos Jogos Olímpicos.

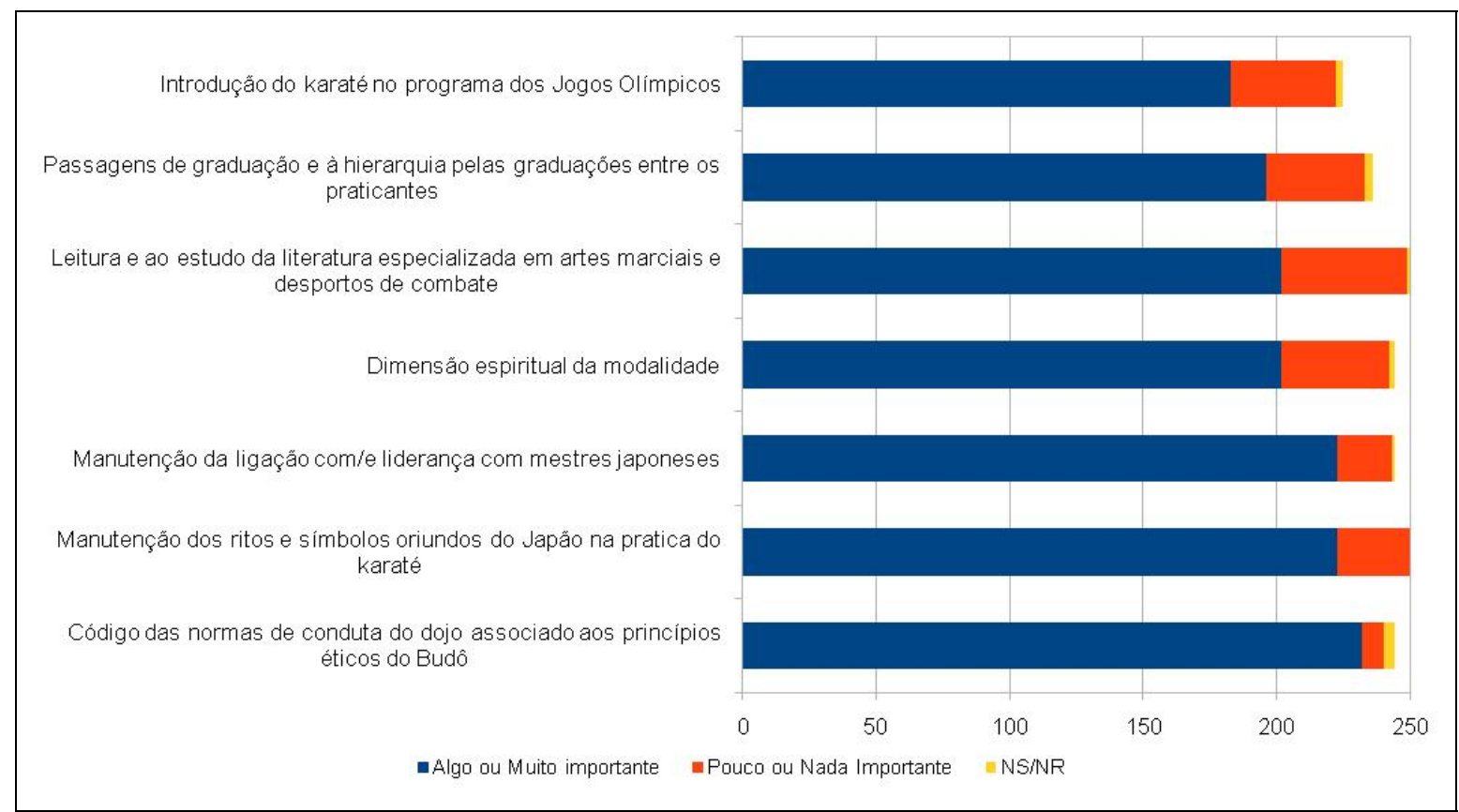

Gráfico 3. Atribuição do grau de importância a aspetos relacionados com a prática do karaté

Os resultados demonstram um caráter multidimensional na orientação e valorização de diferentes aspetos do karaté. Com efeito, dois terços $(66,8 \%, n=163)$ atribuem mesmo muita importância aos códigos do Budô. Demonstram também que mais praticantes de Shotokai valorizam mais aspetos tradicionais dos Budô que outros. No entanto, percentagens expressivas relativizam a importância que atribuem aos ritos e símbolos oriundos do Japão, à hierarquização entre os praticantes e à manutenção da liderança de mestres japoneses. Mais afastado das preocupações dos praticantes está a leitura da literatura relacionada com as artes marciais e desportos de combate.

Há também uma identificação com o "orientalismo", ou seja, o carácter "japonês" da modalidade. Sobre este aspeto, importa sublinhar que dos 244 inquiridos, 93,0\% $(n=227)$ responderam que não foram ao Japão para participar em estágios, treinos ou passagens de graduação; contra $7,0 \%(n=17)$ que dizem que sim. As expensas das viagens foram suportadas pelos próprios.

Quer os resultados das entrevistas, quer os resultados do inquérito do questionário vão ao encontro da teoria sociológica de Bourdieu (1979), que teorizou sobre as diversas modalidades desportivas e as classes sociais. Ele mostra, na sua obra La Distinction (1979), que o fato de se praticar (ou não) tal ou tal desporto não se deve somente aos motivos de ordem económica, mas é preciso ter em conta os fatores de ordem cultural (nível de instrução, origem social) e simbólica. Para o autor, "é ingénuo se supor que os praticantes de um mesmo desporto ou de outra qualquer prática conferem o mesmo significado e sentido da sua ação" (Bourdieu, 1979, p. 232).

De fato, e olhando para a teoria da estratégia dos atores dos sociólogos franceses Crozier e Friedberg (1977), que marcaram durante muitos anos a sociologia das organizações, e que são ainda utilizadas na sociologia das organizações desportivas, o comportamento dos indivíduos, apesar de complexo, "não é determinado": 1) o ator social raramente apresenta objetivos claros e ainda menos projetos coerentes. Estes são múltiplos, mais ou menos ambíguos, mais ou menos explícitos, mais ou menos contraditórios. Ele muda no decurso da ação, rejeitará alguns, descobrirá outros, durante a sua vida. 2) o seu comportamento é ativo. Mesmo se ele é sujeito a limitações e a constrangimentos, nunca é determinado; a passividade é, de certa forma, o resultado de uma escolha. 3) o seu comportamento tem sempre um sentido. Mesmo se incapaz de apresentar 
objetivos claros, ele é racional, sobretudo no aproveitamento de oportunidades. 4) o comportamento apresenta sempre um aspeto ofensivo e um aspeto defensivo. 0 primeiro visa o aproveitamento das oportunidades, tendo em vista melhorar a sua situação. 0 segundo é a procura do alargamento da sua margem de liberdade, logo da sua capacidade de agir.

\section{Conclusão}

Relativamente aos dados apurados, verifica-se um caráter multidimensional na orientação e valorização de diferentes aspetos do karaté. Há praticantes de determinados contextos (estilos) que valorizam o Budô, havendo outros que valorizam a questão desportiva. Diriamos antes "perceção". Os próprios atores do karaté têm perceções diferentes daquilo que é o desporto. Para muitos, é antagónico dos Budo, para outros é uma forma ocidentalizada de Budo (particularmente o Olimpismo, como já vimos).

A dimensão de praticantes de karaté Shotokai parece influenciar a quantidade de praticantes que assumem o Budô como orientação preferencial, revelando-se, por isso, interessante perceber no futuro que razões levam a que estes praticantes façam prevalecer o seu vínculo a estes conceitos e outros não. Percentagens expressivas relativizam a importância que se atribuem aos ritos e símbolos oriundos do Japão, à hierarquização entre os praticantes e à manutenção da liderança de mestres japoneses. Por outro lado as associações desportivas, que têm um papel socializador, consolidam a política de aculturação, constituindo uma instância moralizadora e disciplinar, um fator educativo institucional, um local de socialização e de educação moral, cívica e política.

Os resultados não permitem uma generalização. Eles demonstram uma sectorização de posições. Ao refutar a ideia de competição, alguns praticantes de karaté querem se demarcar do processo de que o ocidente gosta de se amparar. 0 praticante de karaté procura mais o sentido do que a vitória e quando esta é atingida não é considerada como um fim. De facto, os princípios do karaté se acomodam mal a certas conceções que fazem a hipótese de um dado universo, controlável e dado. As representações fornecidas por esta prática oferecem a face de um mundo a construir e em construção permanente. 0 universo do karaté surge como um processo que faz com que a interação entre os adversários responda a um princípio de auto-organização.

Em termos de limites da investigação, realçamos a centralização apenas numa modalidade (karaté). Cremos ser importante o alargamento de estudo semelhante a outras artes marciais e desportos de combate, por forma a se ter outros elementos comparativos.

\section{Referências}

Baudry, P. (1998). La ritualité dans les arts martiaux. Cahiers internationaux de sociologie, 4, 42-44.

Boltanski, L. (1971). Les usages sociaux du corps. Annales Economies Sociétés Civilisations, 26(1), 205-233.

Bourdieu, P. (1979). La distinction : critique sociale du jugement. Paris: Minuit.

Braunstein, F. (2001). Les arts martiaux aujourd'hui. Paris: L'Harmattan.

Briot, A. (2001). Le Budô pris au mot ou la voie des armes suivie à la lettre. Daruma: révue d'études japonaises, 8/9, 21-30.

Brousse, M. (2000). Les origines du judo en France. De la fin du XIX siécle aux années 1950. Historie d'une culture sportive (unpublished Doctoral Thesis). Bordeaux: Université Bordeaux II.

Brousse, M., \& Matsumoto, D. (1999). Judo, A Sport And A Way Of Life. Seoul: International Judo Federation.

Chamberlain, B.-H. (1931). Mours et coutumes du Japon. Paris: Payot.

Champault, F. (2001). Apprendre par corps: problèmes relatifs aux implications psychologiques et morales de l'apprentissage dans les arts de combat au Japon. Daruma: révue d'études japonaises, 8/9, 55-82.

Clément, J.-P. (1985). Étude comparative de trois disciplines de combat (lutte, judo, aïkido) et de leurs usages sociaux. Paris: Université Paris-VII. 
Clément, J.-P. (2001). Les arts martiaux et la socitété française: sociologique historique de l'implantation du jûdô et de l'aikidô. Daruma: révue d'études japonaises, 8/9, 175-199.

Crozier, M., \& Friedberg, E. (1977). L'acteur et le système. Paris: Editions du Seuil.

Cynarski, W., \& Obodynski, K. (2009). A lifestyle of martial arts teachers - example from Poland". Actas do II Congresso Científico de Artes Marciais e Desportos de Combate, 16 e 17 de Maio, Viseu: Instituto Politécnico de Viseu.

Draeger, D. (1973a). The Martial Arts and Ways of Japan. Volume II: Classical Budo. New York: Weatherhill.

Draeger, D. (1973b). The Martial Arts and Ways of Japan. Volume I: Classical Bujutsu. New York: Weatherhill.

Ehrenberg, A., Yahi, J-P., \& Zylberman, P. (1975). Archanges, guerriers, sportif et petits pervers : genèse d'un sport de compétition et destin de la violence physique: analyse des politiques des promoteurs japonais et français du karaté, de l'implantation à l'institution, 1953-1976. Paris: Cordes-Association de Recherche et d'Études l'Environnement.

Elias, N. (2006). O processo civilizacional. Lisboa: Publicações Dom Quixote.

Funakoshi, M. (1979). Gendai Budôkan kenkyû hyôgengoi no shûshû (Pesquisa sobre a conceção das artes marciais atuais - recolha de vocabulário). Budôgaku kenkyû, 11(3), 49-55.

Funakoshi, M. (2001). Notes pour un mémoire sur les arts martiaux: recherche sur la conception actuelle du Budô. Daruma: révue d'études japonaises, 8/9, 125-147.

Gaudin, B. (2009). La codification des pratiques martiales: une approche socio-historique. Actes de la recherche en sciences sociales, 179(4), 4-31.

Gravereau, J. (1990). Le Japon au XXe siècle. Paris: Le Seuil.

Gutiérrez-García, C. (2004). Introducción y desarrollo del judo en España: (de principios del siglo XX a 1965): el proceso de implantación de un método educativo y de combate importado de Japón. León: Servicio de Publicaciones de la Universidad de León.

Gutiérrez-García, C., Rosa, V. A., \& Pérez-Gutiérrez, M. (2010). Introducción de las artes marciales asiáticas en Portugal. Materiales para la Historia del Deporte, 8, 9-17.

Loudcher, J.-F., \& Renaud, J.-N. (2011a). Éducation, sports de combat et arts martiaux. Grenoble: PUG.

Loudcher, J.-F., \& Renaud, J.-N. (2011b). La notion de technique du corps chez Marcel Mauss : de l'ambiguïté à son dépassement, l'exemple du champ sportif. Revue STAPS, 91, 9-27.

Mauss, M. (1950). Sociologie et anthropologie. Paris: PUF.

Min-Ho, K. (1999). L'origine et le développement des arts martiaux: pour une anthropologie des techniques du corps. Paris: L'Harmattan.

Nakiri, F. (2015). Concept of Budo and the history and activities of the Japanese Academy of Budo. IDO Movement for Cultural - Journal of Martial Arts Anthropology, 15(1), 11-25.

Nitobe, I. (1905). Bushidô: the soul of Japan. New York \& London: Putman.

Priest, G., \& Young, D. (2015). Philosophy and martial arts. London: Routledge.

Quivy, R., \& Campenhoudt, L. (1998). Manual de Investigação em Ciências Sociais. (2. a ed.). Lisboa: Gradiva.

Rosa, V. (2007). Encuadramiento legal e institucional de las artes marciales y deportes de combate en Portugal. Revista de Artes Marciales Asiáticas, 2(4), 8-31.

Rosa, V. (2008). Las artes marciales y los deportes de combate en números: una mirada exploratoria sobre los datos numéricos o estadísticos en Portugal. Revista de Artes Marciales Asiáticas, 3(2), 38-49.

Rosa, V. (2015). A prática desportiva do karaté em Portugal: Análise sociológica sobre as identidades, ideologias, comunidades e culturas dos karatecas graduados (cintos castanho e negro) portugueses. Tese de doutoramento (policopiada). Lisboa: IUL-ISCTE.

Rosa, V., \& Stoleroff, A. (2008). Samurais na modernidade europeia: motivações e entendimentos dos karatecas portugueses. Actas do VI Congresso Português de Sociologia, 25 a 28 de Junho, Lisboa: FCSH, Universidade Nova.

Sanzô, M. (1967). SekaiBudôshi (História mundial das artes marciais). Tôkyô: Kôyûsha.

Svinth, J. (2010). Social Uses of the Martial Arts. In T. A. Green \& J. R. Svinth (Eds.), Martial Arts of the World. An Encyclopedia of History and Innovation (Vol. II, pp. xix-xxi). Santa Barbara (CA): ABC-CLIO. 
Theeboom, M., \& Knop, P. (1999). Asian Martial Arts and approaches in Physical Education classes. European Journal of Physical Education, 4, 46-161.

Tokitsu, K. (2000). Budô-Le Ki et le sens du combat. Paris: DésIris.

Tokitsu, K. (2001). Le Budô par-delà les barrières culturelles. Daruma: révue d'études japonaises, $8 / 9,149-173$.

Verthonghen, J., Theeboom, M., \& Cloes, M. (2012). Teaching in martial arts: the analysis and identification of teaching approaches in youth martial arts practice. Archives of Budo, 8(4), 191-202.

\section{Author's biographical data}

Vitor Rosa (Portugal), Docente e Investigador na Universidade de Paris-Ouest Nanterre La Défense (França). Autor de vários artigos científicos sobre artes marciais e desportos de combate e membro da equipa editorial e científica da RAMA.E-mail: vitor.vr@u-paris10.fr. 